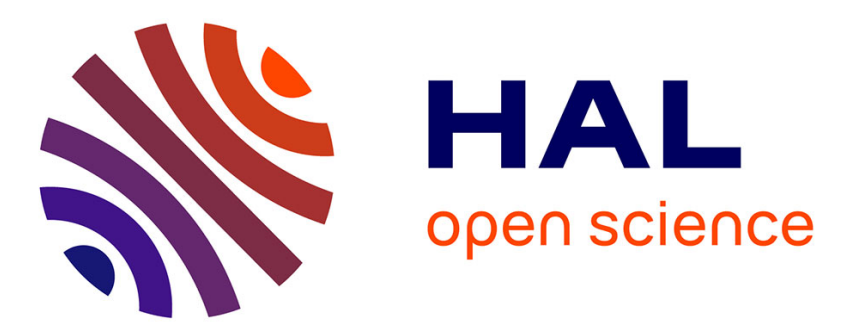

\title{
Visualizing maritime connectivity at national level: the case of LSBCI links of West European countries
}

David Guerrero, Patrick Nierat, Jean-Claude Thill, Emmanuel Cohen

\section{To cite this version:}

David Guerrero, Patrick Nierat, Jean-Claude Thill, Emmanuel Cohen. Visualizing maritime connectivity at national level: the case of LSBCI links of West European countries. Case Studies on Transport Policy, 2021, 9 (4), pp 1818-1824. 10.1016/j.cstp.2021.10.001 . hal-03472145

\section{HAL Id: hal-03472145 \\ https://hal.science/hal-03472145}

Submitted on 9 Dec 2021

HAL is a multi-disciplinary open access archive for the deposit and dissemination of scientific research documents, whether they are published or not. The documents may come from teaching and research institutions in France or abroad, or from public or private research centers.
L'archive ouverte pluridisciplinaire HAL, est destinée au dépôt et à la diffusion de documents scientifiques de niveau recherche, publiés ou non, émanant des établissements d'enseignement et de recherche français ou étrangers, des laboratoires publics ou privés. 


\title{
Visualizing maritime connectivity at national level: the case of LSBCI links of West European countries
}

\author{
David Guerrero ${ }^{+1}$, Patrick Niérat ${ }^{+}$, Jean-Claude Thillł \& Emmanuel Cohen ${ }^{+}$ \\ +Université Gustave Eiffel, IFSTTAR, AME-SPLOTT \\ ¥University of North Carolina at Charlotte, Department of Geography \& Earth Sciences
}

\section{Abstract}

The Liner Shipping Bilateral Connectivity Index (LSBCI), proposed by UNCTAD ${ }^{2}$, aims to measure the quality of maritime transport connections between countries. Although its main geographical scope is the developing world, it is increasingly used by scholars and practitioners within the context of developed countries. But its relevance and applicability remain to be assessed. As a first step in this direction, this paper proposes a visualization of the LSBCl based on Multi-Dimensional Scaling (MDS). The paper is focused on the connections of 10 West European countries among them and with the rest of the world. The MDS visualization clearly shows a core and a periphery in the containerized shipping network. While some proximities between countries can be explained by geographical proximity, others exclusively result from other factors such market structure and network considerations.

\section{Highlights}

- We propose a LSBCl visualization based on Multi-Dimensional Scaling (MDS)

- The visualization clearly shows a core and a periphery in the country network

- There is a pack of European countries positioned at the core of the network

- Some European countries are positioned far away

- The main countries of Europe, Asia and America are very close to each other

- Some peripheral countries are closer to Asia than to Europe

\section{Introduction}

This paper proposes a visualization of the Liner Shipping Bilateral Connectivity Index (LSBCI). This indicator was created by UNCTAD as a complement of the Liner Shipping Connectivity Index (LSCI). While the $\mathrm{LSCl}$ provides a single score for each country, the LSBCl provides scores by country pairs. Both indicators are available on-line on the UNCTAD website ${ }^{3}$.

The two indicators ( $\mathrm{LSCl}$ and $\mathrm{LSBCl}$ ) are based on a handful of individual components related to containerized transport supply at ports. Broadly speaking, they relate to aspects such as the frequency and variety of connections, the maximum vessel size or the number of shipping companies. In the literature, these components have been analysed individually, as estimators of trade and freight rates (Wilmsmeier et al., 2006, Wilmsmeier and Hoffmann, 2008). Interestingly, it has been showed that factors such the number of liner shipping companies operating between two countries was a better estimator of freight rates than the geographical distance (Wilmsmeier and Hoffmann,

\footnotetext{
${ }^{1}$ Corresponding author (david.guerrero@univ-eiffel.fr)

${ }^{2}$ United Nations Conference on Trade and Development

${ }^{3}$ https://unctadstat.unctad.org
} 
2008). This suggests that factors others than geography may play a major role in shaping maritime networks.

In the trade literature, the $\mathrm{LSCl}$ and $\mathrm{LSBCl}$ indexes have been used as such to measure the importance of maritime connectivity and its role on reducing transport costs. These studies are mostly focused on the case of developing countries, for which the lack of good maritime connections often represents an insurmountable barrier to trade (Fugazza and Hoffmann, 2017, UNCTAD, 2017). More recently, these indicators have also been used to assess the maritime connectivity of European countries (UNCTAD, 2020, Tassadit Dial et al., 2021). But its relevance and applicability remain to be assessed. As a first step in this direction, this paper proposes a visualization of the LSBCI links of West European countries based on the method of Multi-Dimensional Scaling (MDS).

By visualizing the structure of the maritime connections of countries, this paper raises a number of interesting features. It brings to light the organization of the country network by distinguishing a core and a periphery. West European countries, which are mostly at the core, are split in several clusters. While proximities among certain subsets of countries can be explained by geographical distance, others seem more linked to other factors such as market structure and network considerations. This work shows that in the case of West European countries, UNCTAD connectivity indicators appear to be either too narrow in focus to be useful for policy-makers or too general, and therefore failing to distinguish the maritime connections that really matter for each country. The results of this work may be useful for the current users of UNCTAD maritime connectivity indicators (ex. policy makers, scholars) to understand their relevance and limitations.

This study aims to contribute to the literature in two ways. On the one hand, it tests the pertinence of a method (MDS) for the visualization of bilateral connectivity indicators. In this respect, this research follows former studies using port level data to visualize maritime networks (see Ducruet, 2020 for a recent critical review of this field). On the other hand, it raises questions about the relevance of the $\mathrm{LSBCl}$ indicator itself in the European context. Given the recent literature, there is an urgent need to understand how well suited the LSBCl is to reflect the situation of European countries.

Studies analysing maritime connectivity at the level of countries are rare, perhaps because being at the level of countries was considered as the poor cousin of port-level network analysis. An intermediate level of analysis (countries) may have some advantages though, by reducing the complexity of port-level visualizations (see, for example, Ducruet et al., 2010 or Pais-Montes et al., 2012) and reducing the instability of port positions when there are changes in shipping services (Rodrigue, 2020). Connectivity indicators at the national level also allows for making use of a number of statistics that are only available on the national level, notably trade or national indicators such as the Logistics Performance Index (Fugazza and Hoffmann, 2017, Arvis et al., 2016).

As mentioned before, the LSBCl indicator has been mostly used for general comparisons with trade flows, quantifying the relationship between both. In fact, such research quantifies how the $L S B C l$ is correlated with the intensity of bilateral trade, eventually including other indicators such country GDP (Saeed et al., 2020). Studies specifically analysing the LSBCI indicator from a critical perspective are lacking, with few exceptions (Nierat and Guerrero, 2019). This research helps to fill this void by proposing a visualization based on the MDS method of dimensionality reduction, which is capable to summarize the main distances between countries but avoiding the noise of port-level networks. 
The remainder of the paper is structured as follows. The next section discusses the data and the method employed. Then we present the visualization. It is followed by an interpretation and discussion of the analytic results. The last section concludes the paper.

Data and methodfor this study we employed the Liner Shipping Bilateral Connectivity Index ( $L S B C l)$, using the most recent release of the data, which is 2020. For each country pair, the $L S B C I$ is the average of five normalized components (Fugazza and Hoffmann, 2017): (a) the number of transshipments required to get from country A to country B (NbTrans); (b) the number of direct service connections common to countries $A$ and $B$ (DirectC); (c) the number of common service connections by country pair with one transhipment (IndirectC); (d) the level of competition on services that connect country A to country B (NbCompanies); (e) the size of the largest ship on the weakest route connecting country A to country B (ShipSize).It is available for 168 countries or territories across the globe. In this study we have only taken into account 161 countries.

\section{Multi-Dimensional Scaling (MDS)}

The method used to visualize the $L S B C I$ is MDS. This so-called dimension-reduction technique allows to place entities (here, countries) in an abstract cartesian space of $n$ dimensions based on on the pairwise distances (or similarities) between these entities (Kruskal and Wish, 1978). The metric used for this purpose is the inverse of $L S B C I(1 / L S B C I)$, varying between 1 for very close countries and infinite for very distant ones. MDS provides a visualization of a dataset such as ours in the form of a space of low dimensionality, typically one, two or three dimensions.

The quality of MDS is measured by stress measures. This value depends on the number of iterations and dimensions. The result is considered to be acceptable when the stress is below 0.20 (Borgatti et al., 2013). The stress values obtained in this work are presented in table 1 and in figure 1 . For 2 dimensions, the stress is 0.273 when considering all the countries $(n=161)$, which is marginally acceptable, but highlights the need for taking into account a third dimension to provide a more complete representation of covariances embedded in the LSDCI matrix and a richer interpretation of the patterns depicted by the MDS visualization results. When considering only the European countries, the results are better.

\begin{tabular}{|c|c|c|c|c|c|}
\hline & Number of dimensions & 2 & 3 & 4 & 5 \\
\hline \multirow{2}{*}{$\begin{array}{l}\text { All countries } \\
n=161\end{array}$} & Kruskal's stress & 0.273 & 0.204 & 0.165 & 0.139 \\
\hline & Iterations & 246 & 293 & 353 & 389 \\
\hline \multirow{2}{*}{$\begin{array}{l}\text { Europe } \\
n=30\end{array}$} & Kruskal's stress & 0.239 & 0.167 & 0.125 & 0.107 \\
\hline & Iterations & 181 & 250 & 416 & 292 \\
\hline
\end{tabular}

$\underline{\text { TABLE 1. MDS RESULTS }}$ 


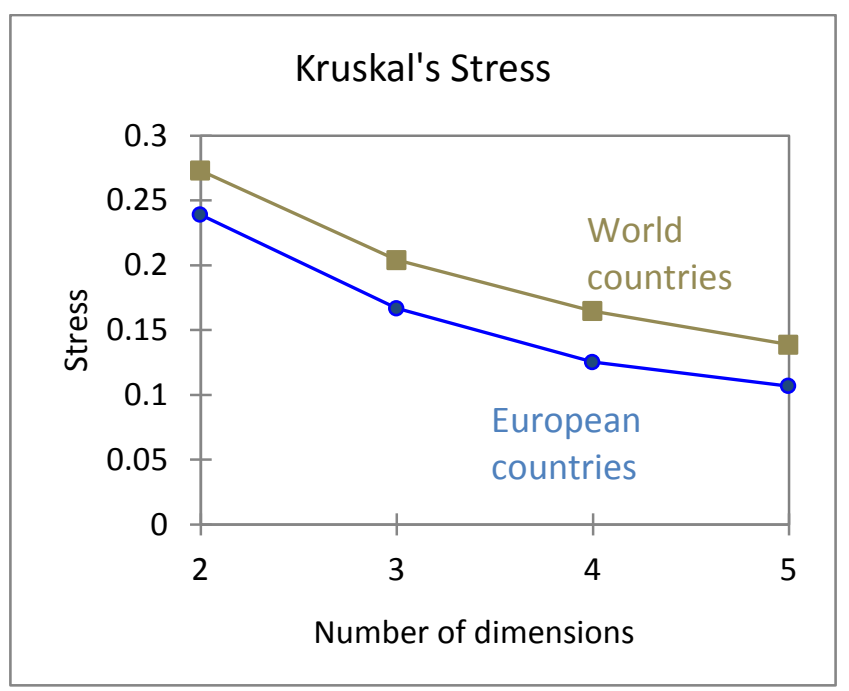

FIGURE 1. MDS KRUSKAL'S STRESS 


\section{A tentative visualization}

Figure 2 shows the result of the MDS model applied to the dataset's 161 countries when the first two dimensions are considered. On this figure, the circles are countries labelled by their ISO-3 digit codes $^{4}$; colours denote the world regions, while the size of each circle is proportional to the value of the best $\mathrm{LSBCl}$ connection of the country.

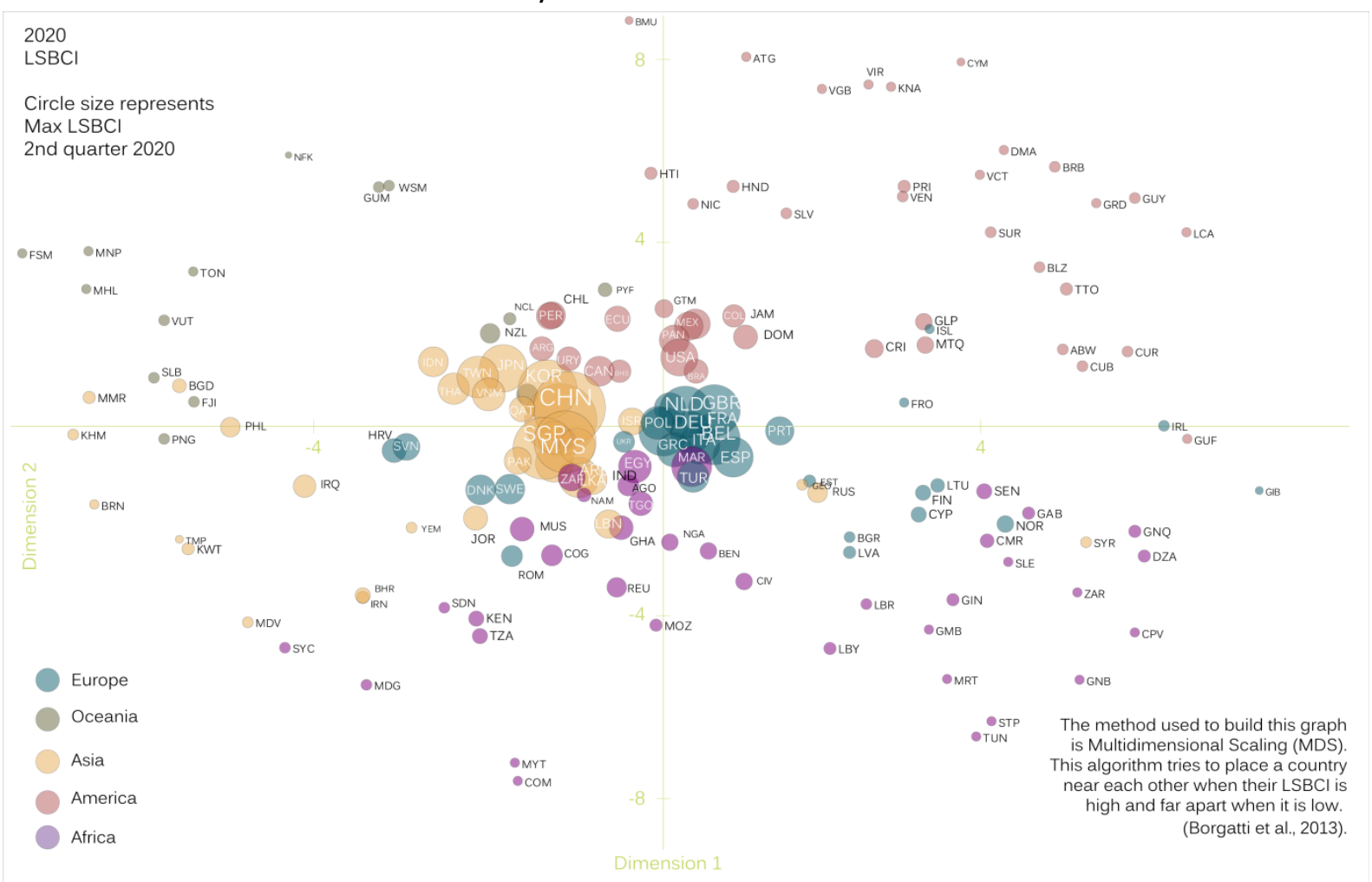

\section{FIGURE 2. MDS VISUALIZATION OF THE LSBCI. DIMENSIONS 1 AND 2. ALL COUNTRIES}

The centre of the MDS space is comprised of clusters of countries from several world regions, mainly Europe (Netherlands, United Kingdom, Greece,...), Asia (China, South Korea, Malaysia...), America (US, Canada,...), and a few African countries (Morocco and Egypt). Many countries positioned in the core are represented by large circles, meaning that they are well connected overall. In the periphery, there are many countries from all the World regions; for Europe, Ireland is at the very right of the graph, while Croatia, Slovenia, Sweden and Denmark are on the opposite side, although in a more central position. All countries positioned at the periphery have low overall connectivity.

Figure 3 provides an zoomed-in view of figure 2, on which we also included the strongest LSBCI links between countries within the same region as well as between regions $(\mathrm{LSBCl}>0.35)$ to enhance the interpretability.

\footnotetext{
${ }^{4}$ The list of ISO codes is available on-line https://www.iso.org/obp/ui/\#search
} 


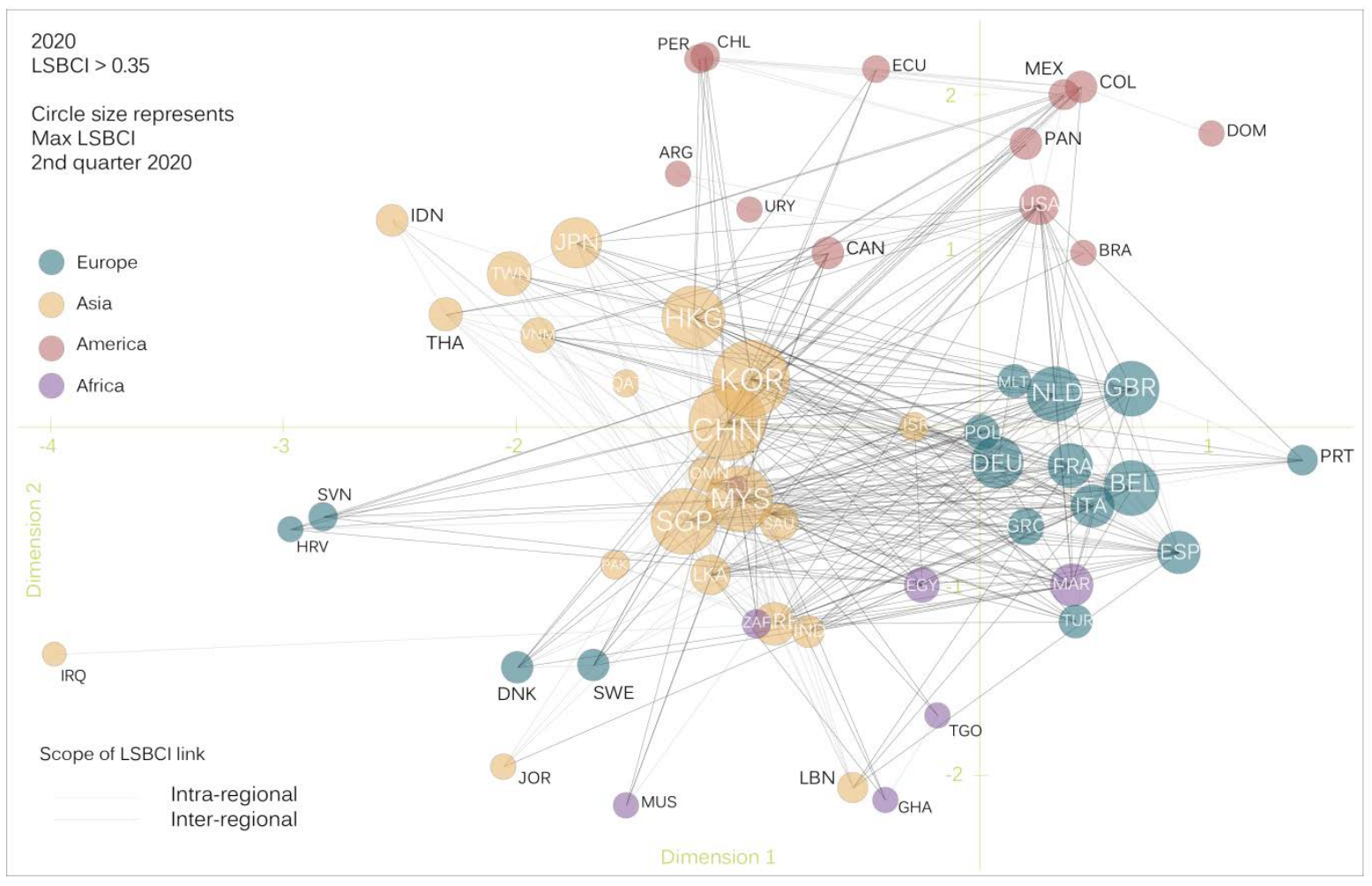

FIGURE 3. MDS VISUALIZATION OF THE LSBCI. DIMENSIONS 1 AND 2. COUNTRIES INVOLVED IN TOP LINKS

\section{$\underline{(L S B C l>0.35)}$}

This visualization clarifies the situation of centrally positioned countries. All the countries in the figure have at least one $\mathrm{LSBCl}$ connection of more than 0.35 . It can be observed that:

- Best connected countries are at the core (Asia, Europe, America) while less well connected ones are at the periphery.

- Each large world region has many of their member countries positioned in fairly close proximity to each other, thus forming a well identifiable core.

- Europe's core is split in several groups, including a main grouping with the Netherlands, France, Germany, Belgium, and Italy on the right side, and another on the left, with Sweden, Denmark, Slovenia and Croatia. Why Sweden and Denmark are away from the main pack of European countries? Is this just accidental or are there compelling reasons? In the next section we examine some of the factors that account for the position of European countries.

- Intra-regional links. Compared to the other regions, Europe contains many coastal countries with relatively high $\mathrm{LSBCl}$ scores. A significant proportion of the best $\mathrm{LSBCl}$ connections of $E U$ countries are among countries of Europe. In fact, for most countries, the 5 best connections are with other European countries.

- It should be noted that these intra-European high scores do not necessarily reflect the routes which are effectively used by European shippers.

- Some African countries are positioned close to Europe, but the majority of them are close to Asia. This may reflect their intermediacy on shipping routes spanning the globe, particularly 
from Asia (including the Indian subcontinent and Southeast Asia) to South and North America, but one can also conjecture that China's quickly developing One Belt One Road system has had a role to play.

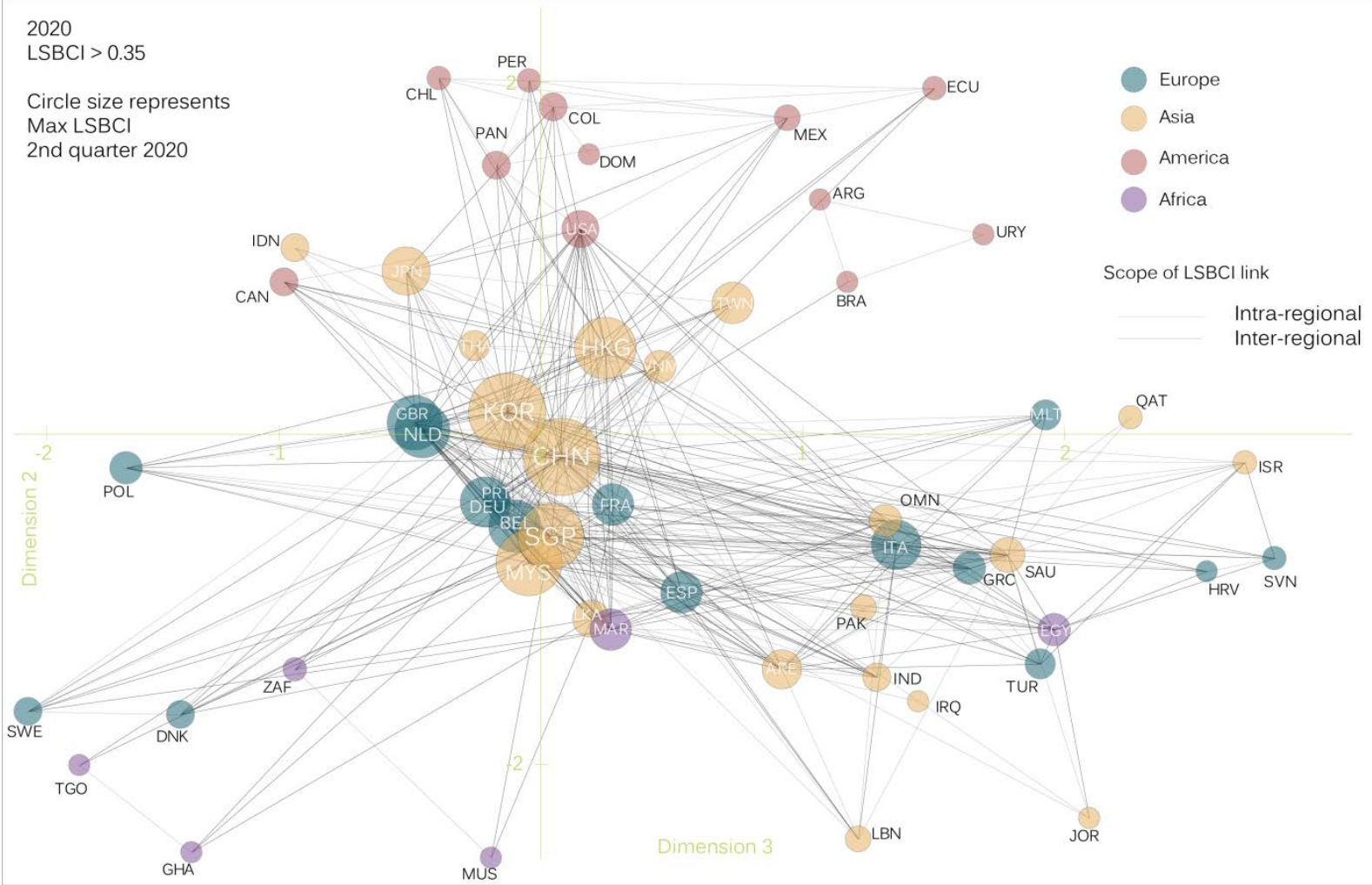

FIGURE 4. MDS VISUALIZATION OF THE LSBCI. DIMENSIONS 3 AND 2. COUNTRIES INVOLVED IN TOP LINKS

\section{(LSBCl>0.35)}

The addition of a third dimension to the MDS solution brings new insights to the analysis of maritime connectivity across the globe. Dimension 3 (figure 4), which would be in a direction orthogonal to dimensions 1 and 2 discussed so far, reveals a split among the large European countries in two groups: roughly the Atlantic/Northern Range vs the Mediterranean. European countries are spread quite broadly from the far left to the far right of the figure.

Also, we can notice that dimension 3 splits Asian countries with the main grouping in the centre left (East Asian countries, such as China, Japan, Korea, and Singapore), while a second and more diffused grouping is found on the right side (with southwest and south Asian countries predominantly, including, Iraq, Oman, Israel, India, Pakistan, and others). Interestingly, the latter grouping aligns well with the Mediterranean grouping, while the former aligns with the Atlantic countries.

\section{Interpretation}

While the graphs in the above figures are rather enticing, their scientific value is closely tied to the interpretation that can be assorted to the observed layouts, and fundamentally why a pair of countries A \& B may be close or far. Two sources of explanation can be advanced : a) The strength of the links between $A$ and $B ; b$ ) The more or less common connections of $A$ and $B$ with third countries that indirectly would create affinities between countries. In that respect, it would seem that dimensions 1 and 2 bring out the geography of countries and their inter-regional vs intra-regional 
connections. On the other hand, dimension 3 separates countries in ways that transcend geography to some extent, with groupings with high connectivity (at the core) vs others with lower connectivity (at the periphery).

\section{Intra-regional connections}

Figure 5 presents the first two dimensions of an MDS applied only to European countries, leaving out countries outside of Europe entirely. The stress is better than for the former figures based on all 161 countries. The resulting figure is similar to figure 3 , which stressed how influential the closely knit web of connections among European countries is to structure the fundamental organization of maritime connectivities at the global scale. The positions of some Scandinavian and Balkan countries are closer to the main grouping, however.

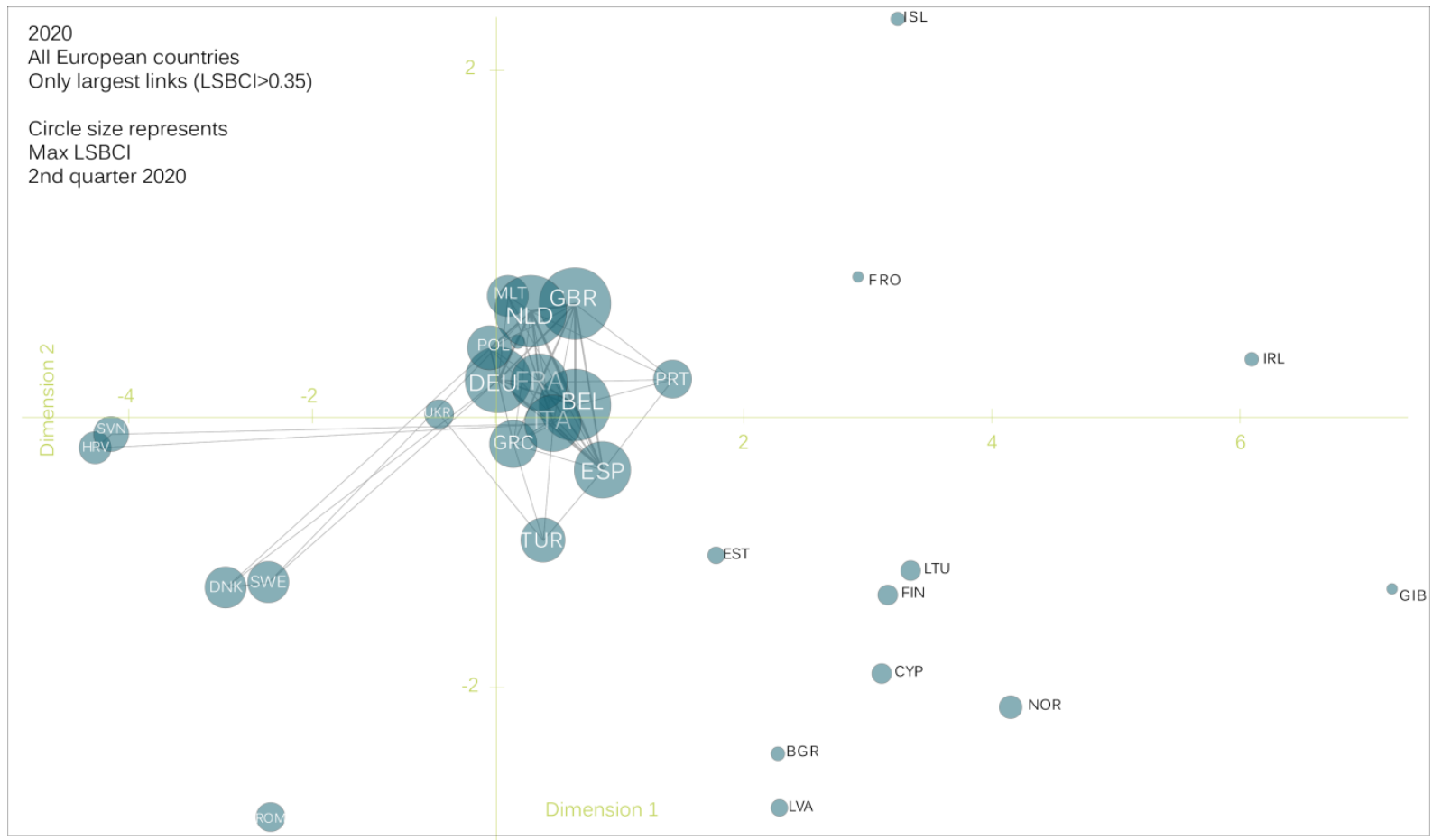

Inter-regional connections

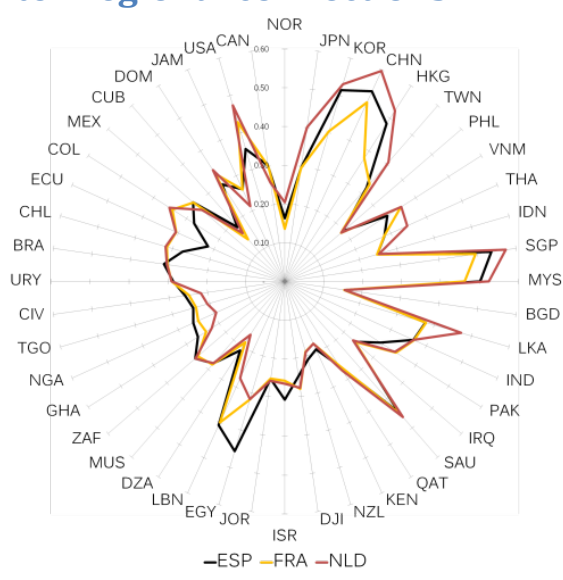

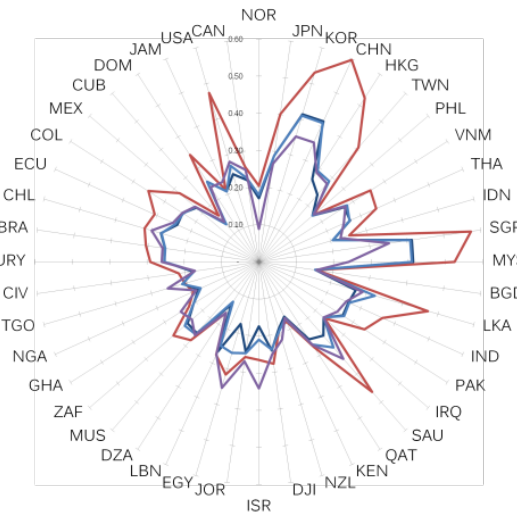

-NLD -SWE -DNK - HRV

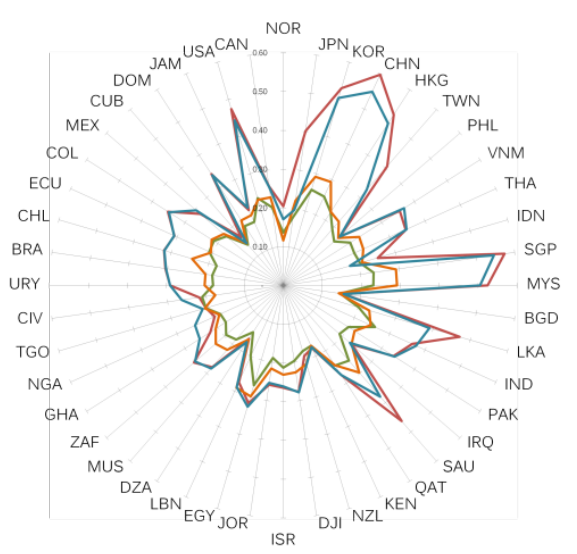

-NLD -RUS -ROM -BEL 
Figure 6 presents three rose plots that compare a selection of interregional connections of some European countries in terms of their LSBCl scores with countries in other parts of the world. The Netherlands (in red) is used as a reference for the comparisons in all three panels of the figure. On the left, Spain and France often have less good connections but closer to the levels of the Netherlands. At the centre, the Scandinavian countries and Croatia have considerably weaker connections than the Netherlands, with few exceptions. In the right panel, Belgium is shown to have scores similar to the Netherlands, while Russia and Romania have considerably lower scores. Therefore, these visualization forms help corroborate the strong influence of geography and of economic and institutional ties internal to regions on the functional relationship embedded in shipping networks and their connectivity properties.

\section{Discussion}

\section{MDS Visualization}

The MDS method appears to be particularly useful to preserve high-dimensional distances in a space with two or three dimensions. In the case of the $L S B C l$, it allows the visualization of the positions of regions and countries, and how they are spread between the core and the periphery of the maritime network. This kind of visualization can be combined with the representation of the main links (LSBCl>0.35). Adding more links would imply a significant loss in the readability of the graph. Since MDS is an approximation of a high-dimensional space, certain distances are not well represented in a two-dimension space. It is the case, for example, of Japan and Argentina, which appear close together on dimensions 1 and 2 (figure 3 ) but in reality are quite far, as shown on dimension 3 (figure 4). Another important aspect of MDS is that the interpretation of distances between countries is not always straightforward: in some cases it is related to intra-regional distances while, in other cases, it is more driven by inter-regional links.

\section{The LSBCI}

Beyond the issues related to the visualization method, there are also issues related to the LSBCl itself. An earlier paper listed some of them (Niérat and Guerrero, 2019). These issues are, for example, the difficulty to interpret small variations on $L S B C I$ from one year to another, which do not necessarily reflect major changes on the country's connectivity. Another issue of the $L S B C l$ is that a high index between two countries (ex. Morocco and Spain), results from inter-hub connections, and not from the importance of the containerized trade between the two countries (Niérat and Guerrero, 2019).The current study raises new concerns specific to the European case :

- The best connections are intra-regional. In Europe, most of the intra-regional trade is noncontainerized (land-based shipping, RoRo services,...).

- The high $\mathrm{LSBCl}$ scores of the main European countries partly result from the fact that Europe encompasses many countries, which artificially increases the regional connectivity (gravity effect on the MDS) as compared to, for example, the United States. This gap in LSBCl score does not necessarily reflect a real gap in the connectivity of the latter.

- Similar LSBCl scores can result from different configurations. To illustrate these differences, figure 7 shows the breakdown of the five LSBCI components for the relationships between 
France and a selection of countries in Asia and America in 2016. On the left, we see that equal LSBCl scores of the connections France-Philippines and France-Honduras result from different combinations of components. Most notably, services between France and Honduras involve a much smaller number of shipping companies than for the Philippines and the number of transshipments required in much larger. A similar differences can be observed on the graphs for the France-Canada and France-Thailand services, on the righthand side. Thus, to fully understand and interprete the relative positioning of countries on the MDS output must account for differences and similarities holistically.

France-Philippines (LSBCl=0.34)

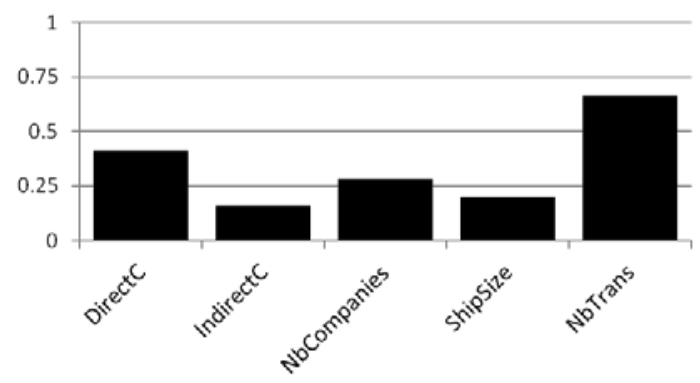

France-Honduras ( $\mathrm{LSBCl}=0.34)$

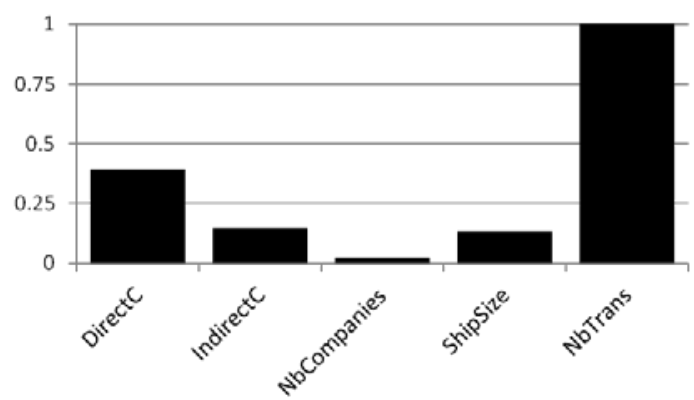

France-Canada ( $\mathrm{LSBCl}=\mathbf{0 . 4 6})$

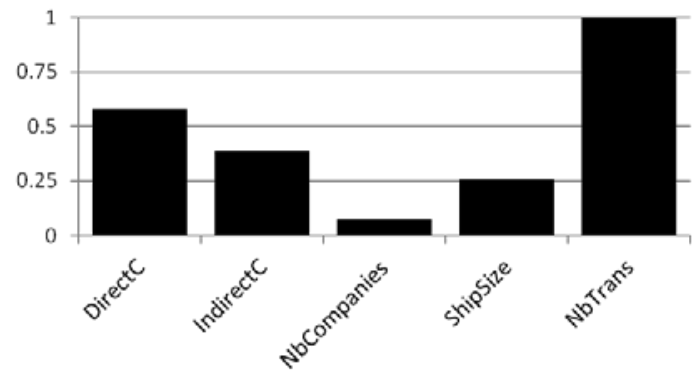

France-Thailand ( $\mathrm{LSBCl}=0.46)$

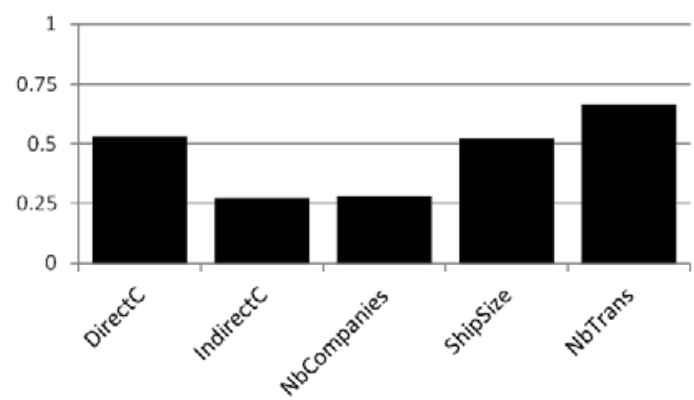

FIGURE 7. CONFIGURATIONS OF INDIVIDUAL COMPONENTS ON PAIRS OF SERVICES WITH IDENTICAL LSBCI SCORES (2016 DATA).

\section{Conclusion}

This work proposed a visualization of the LSBCI country network using Multi-Dimensional Scaling (MDS). Methodologically, MDS appeared as a particularly useful tool to visualize the positions of regions and countries. This kind of visualization can be combined with the representation of the main links between countries. Adding more links would imply a significant loss in the readability of the graph. Since MDS is an approximation of a high-dimensionality space, certain distances were not well represented in a two-dimension space. Therefore the visualization of the third dimension could be insightful, especially when the number of countries is high.

This work also brought to light the core/periphery organization of the country network by distinguishing a core and a periphery in the international shipping system. West European countries, which are mostly at the core, are split in several clusters. The main grouping contains the countries hosting the largest ports such the Netherlands, Germany, United Kingdom, Belgium or Italy. Sweden and Denmark, on one side, and Slovenia and Croatia, on the other side, appear as separated 
groupings, which are relatively close to each other. Some of these proximities among countries can be explained by geographical distance, while others seem more linked to other factors such market structure and network considerations. When two countries share common shipping services, they tend to be close, no matter how distant they are physically.

It should be noted that the high connectivity scores indicate that intra-European links do not necessarily reflect the routes which are effectively used by European shippers. Also, most of the intra-European trade is not containerized (land-based shipping by rail or trucks, RoRo services,...). To overcome this issue, connectivity indicators using RoRo shipping are promising (De Langen et al., 2016); however, to be fully operational, they should include the bilateral relationships (port to port or country to country) rather than be limited to nodal attribution. Moreover, in Europe there are significant volumes of national trade passing through ports of neighbouring transit countries, such for example between France/Germany and the Benelux ports.

To sum up, in the case of Western Europe, UNCTAD connectivity indicators appear to be either too narrow in focus to be useful for policy-makers or too general, and therefore failing to distinguish the maritime connections that really matter for each country. The results of this work may be useful for the current users of UNCTAD maritime connectivity indicators (ex. policy makers, scholars) to understand their relevance and limitations.

The analysis of LSBCl scores conducted for this study suggests that further work is fruitful to better understand the structures of shipping networks globally and globally, particularly as they related to the response of shipping line operators, trade relationships between countries, trade agreements, and efficiencies of port and terminal operators across countries. While our analysis was crosssectional, a longitudinal analysis would enhance our understanding of how the maritime shipping systems adjusts to internal and external influences. Also, a study of each of the five components of the $\mathrm{LSBCl}$ individually as to their specific association with the dimensions extracted by the MDS algorithm, and of the variations of such association across world regions, would be informative for maritime studies.

\section{References}

Arvis, J. F., Duval, Y., Shepherd, B., Utoktham, C., \& Raj, A. (2016). Trade costs in the developing world: 1996-2010. World Trade Review, 15(3), 451-474.

Borgatti, S. P., Everett, M. G., \& Johnson, J. C. (2018). Analyzing social networks. Sage.

De Langen, P. W., Udenio, M., Fransoo, J. C., \& Helminen, R. (2016). Port connectivity indices: an application to European RoRo shipping. Journal of Shipping and Trade, 1(1), 1-19.

Dial, R. T., Figueiredo de Oliveira, G., \& Schaffar, A. (2021). The spatial dimension of maritime connectivity: The case of Northern Europe and the Mediterranean. Canadian Journal of Regional Science/Revue canadienne des sciences régionales, 44(1), 35-45.

Ducruet, C. (2020). The geography of maritime networks: A critical review. Journal of Transport Geography, 88, 102824. 
Gomez-Paz, A., Sanchez, R.J. (2020) Conexiones de carga marítima entre Asia Pacífico y América Latina, Análisis de fletes de transporte, sus determinantes y restricciones, CEPAL, Documentos y Proyectos.

Fugazza, M., \& Hoffmann, J. (2017). Liner shipping connectivity as determinant of trade. Journal of Shipping and Trade, 2(1), 1-18.

Hoffmann, J., Saeed, N., \& Sødal, S. (2020). Liner shipping bilateral connectivity and its impact on South Africa's bilateral trade flows. Maritime Economics \& Logistics, 1-27.

Kruskal, J. B., and M. Wish. 1978. Multidimensional Scaling, Sage University Papers Series. Quantitative Applications in the Social Sciences. 11. Beverly Hills, CA: Sage Publications.

Niérat P. \& Guerrero D. (2019) UNCTAD maritime connectivity indicators: review, critique and proposal. Article No. 42 - UNCTAD Transport and Trade Facilitation Newsletter N ${ }^{\circ} 84$ - Fourth Quarter 2019

Rodrigue, J. P. (2020). The geography of maritime ranges: interfacing global maritime shipping networks with Hinterlands. GeoJournal, 1-14.

Saeed, N., Cullinane, K., \& Sødal, S. (2020). Exploring the relationships between maritime connectivity, international trade and domestic production. Maritime Policy \& Management, 1-15

UNCTAD (2017) Review of maritime transport, United Nations Publications, https://unctad.org/system/files/official-document/rmt2017_en.pdf

UNCTAD (2020) Handbook of Statistics - Maritime transport. Fact sheet \#15: Maritime transport indicators

Wilmsmeier, G., Hoffmann, J., \& Sanchez, R. J. (2006). The impact of port characteristics on international maritime transport costs. Research in Transportation Economics, 16, 117-140.

Wilmsmeier, G., \& Hoffmann, J. (2008). Liner shipping connectivity and port infrastructure as determinants of freight rates in the Caribbean. Maritime Economics \& Logistics, 10(1-2), 130-151.

Xu, M., Pan, Q., Xia, H., \& Masuda, N. (2020). Estimating international trade status of countries from global liner shipping networks. Royal Society open science, 7(10), 200386. 